\title{
Designing packaging to support the safe use of medicines at home
}

\author{
James Ward $^{\mathrm{a}, *}$, Peter Buckle ${ }^{\mathrm{b}}$, P. John Clarkson ${ }^{\mathrm{a}}$ \\ a Engineering Design Centre, Engineering Department, University of Cambridge, Trumpington Street, Cambridge CB2 1PZ, UK \\ ${ }^{\mathrm{b}}$ Robens Centre for Public Health, Faculty of Health and Medical Sciences, Duke of Kent Building, University of Surrey, Guildford GU2 7TE, UK
}

\section{A R T I C L E I N F O}

\section{Article history:}

Received 30 September 2007

Accepted 15 December 2009

\section{Keywords:}

Inclusive Design

Labelling

Medication error

Methotrexate

Medicines

Older adult

Packaging

Patient safety

Usability

\begin{abstract}
A B S T R A C T
In the light of a number of serious incidents in the UK resulting from accidental overdoses of methotrexate, this study investigated how the design of methotrexate packaging can influence patient safety, and aimed to collect evidence to provide a basis for the development of new concepts for revised designs by the pharmaceutical industry. The research found that patients using methotrexate experience a number of difficulties in using their medicines packaging, and as a result, resourcefully adopt a variety of "coping strategies" which may increase the risk of dosing errors. By investigating both the practice of methotrexate users, and the design of the system that supports methotrexate use, additional problems were observed across the healthcare system, meaning that the function of medicines packaging in ensuring safety may be even more critical than first suspected. As a result of this research the National Patient Safety Agency responded with a UK-wide programme of work to improve safety for patients, and continues to work with the pharmaceutical industry to develop more user-friendly packaging and labelling.
\end{abstract}

(c) 2010 Elsevier Ltd. All rights reserved.

\section{Introduction}

\subsection{The packaging and labelling of medicines in the UK}

Across the UK medicines are usually packaged in two types of container: in bottles with push-down-and-turn closures (a type of "child-resistant closure" or CRC) and in blister packs, consisting of one or more blister strips, each containing a number of tablets. Labelling provides the identity of the medicine and the patient it is intended for, its strength, dose, route and contraindications. Packaging and labelling, therefore, play a crucial role in housing and protecting medicines and in conveying a range of information to users. However, the medicines within these containers are becoming ever more diverse, complex and potent (Audit Commission, 2001), increasing the potential for harm and the corresponding need for safe management of medicines. Yet, research has shown that around half of all patients in the UK are not adherent to their medication regimen (Wright, 1993) and evidence abounds of medicines-related harm both in hospital and community care (DH, 2004).

There are many reasons why substandard adherence can occur (Marinker and Shaw, 2003), but poor design of the packaging or labelling of medicines is known to be a noteworthy contributing factor. Through its Web site, the Institute of Safe Medication

\footnotetext{
* Corresponding author.

E-mail address: jrw38@cam.ac.uk (J. Ward).
}

Practices (ISMP) in the US provides many examples of unclear and confusing designs, which have led to the potential for error or even deaths of patients. Indeed, based on figures from the ISMP, Kenagy and Stein have estimated that as many as 10,000 patients are injured or killed each year due to labelling and packaging related issues (Kenagy and Stein, 2001).

More specifically, many studies have reported on a variety of such issues experienced by patients, resulting in outcomes ranging from mild inconvenience to serious medical complications or even death. These problems include difficulties in opening containers (Atkin et al., 1994; Beckman et al., 2005; Clark, 2002; Donaghy and Wright, 2003; DTI, 1999; Thwaites, 1999), mix-ups between medicines due to similarity in appearance (BMJ, 2003; Cramer, 1998; DH, 2004; Toogood, 2002), problems with reading and understanding labelling and instructions (Bernardini et al., 2001; Bernardini et al., 2000; Braus, 1993; Kalsher et al., 1996; Moisan et al., 2002; Sansgiry et al., 1997) and difficulties remembering key information about their medicine (Kerr et al., 2003). Most studies suggest that problems are commonplace, particularly for older users of medicines.

Successful use of the packaging and labelling of medicines requires a degree of both physical (visual and muscular) and cognitive ability to perform tasks such as opening containers and reading and understanding instructions. Not only may the individual tasks, such as gripping, squeezing or turning, be difficult for patients, but combinations of two or more of these actions may require to be performed simultaneously, meaning that opening 
packaging can create difficulties in coordinating these movements (DTI, 1999).

One of the reasons for these difficulties is the fact that a patient's abilities can be drastically reduced by their medical condition, as in the cases of rheumatoid arthritis on physical strength and dexterity, and uncontrolled diabetes on visual ability through diabetic retinopathy. In addition, the side-effects of the very medication they are taking can compromise adherence, for example by inducing forgetfulness and hence reducing a patient's ability to take their medicine according to their plan of care. Difficulties in using medicines can also be particularly pronounced for older users due to the decline in physical and cognitive ability that is associated with the ageing process (Cramer, 1998). Yet it is these older people who are the heaviest users of medicines; in the UK four out of five people aged over 75 take prescribed medicines ( $\mathrm{DH}, 1998$ ), and 60\% of prescriptions in England were dispensed to men and women aged 60 and over in 2007 (The Information Centre, 2008).

\subsection{The packaging and labelling of methotrexate in the UK}

In light of the types of problem illustrated so far in this paper, the design of the packaging and labelling of a medicine called methotrexate has been under examination by the National Patient Safety Agency (NPSA), a body which was formed to assess and assist improvement in patient safety in the UK's National Health Service (NHS). When taken at the right frequency and dose, methotrexate is a safe medicine. However, through analysing UK records over a 10-year period, the NPSA identified 137 incidents associated with methotrexate tablets, which led to some 25 deaths and 26 cases of serious injury due to unintentional overdoses of the drug (NPSA, 2003). It was suspected that, in some of these cases, poor design of the packaging and labelling of methotrexate could have contributed to the error. Consequently, the NPSA funded a programme of research to determine how and why packaging and labelling might contribute to such errors and how they might be reduced or removed in the future. This research formed one of three, parallel, NPSA studies, aimed to improve safety associated with the use of methotrexate. The others involved the development of a new patient treatment diary and modification of IT systems in General Practitioners' (GP) surgeries and community pharmacies. This research is now concluded, and a summary of findings and recommended practice for the NHS can be found through the NPSA's web site (www.npsa.nhs.uk).

Almost no published evidence is available on the demographics of methotrexate users and their use of methotrexate in the UK. Harris reports that annually around 50,000 patients receive oral methotrexate treatment from the NHS in England and Wales (Harris, 2005). The vast majority of these are rheumatological and dermatological patients. Given the aforementioned effects of arthritis on strength and dexterity, this may mean that the majority of methotrexate users may experience a reduction in their ability to open medicines containers.

At the time of this study (2003), methotrexate in the UK was normally administered to rheumatology and dermatology patients utilising tablets of $2.5 \mathrm{mg}$ and $10 \mathrm{mg}$, being packaged loose in packs of 100 or in blister packs of 28 . Methotrexate has a number of characteristics which underscore the importance of appropriate dosing by patients. Its dose is highly patient-specific, ranging typically from between 5 and $25 \mathrm{mg}$. However, the frequency with which methotrexate is taken is unusual; for rheumatology and dermatology patients methotrexate is normally taken once a week, rather than on a daily basis like most medicines. Indeed, of the 13,000 medicines licensed for use in the UK, only six are taken on a weekly basis (Adcock, 2004). Methotrexate can also be classed as a narrow therapeutic index drug, meaning that it is very important for the correct dose to be given, with little room for error. Frequent blood monitoring is therefore required to ensure that an appropriate dose is given to the patient.

\section{Study aims}

Given the potential for both inconvenience and serious error for patients, the characteristics of methotrexate and its users underscore the importance of suitable packaging and labelling design. The research, therefore, aimed to investigate current practice in the UK healthcare system with solid oral medicines (i.e. tablets), with a focus on the experiences of rheumatology and dermatology patients in using methotrexate. To realise this aim, the following objectives were formed:

1. Investigate patients' practice in using solid oral medicines and determine how and why patients currently take, and sometimes fail to take, the right dose of their medicines.

2. Develop recommendations as to how the safe use of medicines by patients can be encouraged through the design of medicines packaging and labelling.

3. Present problems associated with packaging and labelling design to manufacturers of methotrexate, to encourage new developments, where necessary.

However, before any new developments are integrated into the healthcare system (including the patient's home), it is important to consider their interaction with the other elements of the system. Without such a "systems" understanding, new designs are unlikely to be optimal as they may inadvertently create further difficulties (Clarkson et al., 2004; Carayon et al. 2006). Indeed, in addition to the packaging and labelling of methotrexate, a number of mechanisms help to ensure the safe and suitable delivery of this drug to the patient. From patient assessment before methotrexate is given, to blood test monitoring, much information is collected, analysed and transferred between a number of stakeholders, often through a "shared-care" arrangement, governed by a shared-care protocol. These set out responsibilities for the patient's care, between the GP (e.g. for monitoring blood tests), hospital (e.g. for monitoring the patient's general progress) and patient (e.g. for reporting side-effects).

Given the need for a systems understanding, a further objective was formed:

4. Investigate the healthcare system associated with methotrexate packaging and labelling and determine where it can fail to support patient safety.

\section{Research methods}

The research reflected the need for a systems understanding by utilising a number of different research methods to investigate practice across primary and secondary care, and in the patient's home (Buckle et al., 2006; Clarkson et al., 2004).

To investigate the healthcare system, healthcare professionals from the NHS were interviewed using unstructured interviews. Maps were developed of the delivery process of methotrexate, from manufacturer to patient, and the healthcare system surrounding this process. The maps were used to support two risk analysis sessions with healthcare practitioners, to identify "risky" areas of the healthcare system.

Patients' practice was investigated after receiving ethics approval from the Local Research Ethics Committee. Semi-structured interviews took place in their homes and patients were videotaped as they opened various types of medicines packaging. 
Patients were encouraged to discuss any problems they had in using their medicines and to describe their thoughts during the observational exercise.

Based on the findings, basic design requirements for future packaging and labelling were developed. These formed the basis for the development of a number of design "concepts". A paper-based assessment was also conducted, in the form of a "design exclusion assessment" which investigated the degree to which current designs of packaging and labelling exclude patients from using them. The findings from the research and the design concepts were presented to manufacturers of methotrexate packaging and labelling, with a view to encouraging further improvements for users.

\subsection{Interviews}

12 patients and 10 healthcare professionals were interviewed, either face-to-face or by telephone. The characteristics of these interviews are summarised in Table 1.

After receiving ethics approval, patients were recruited through reviews of GP-practice records of patients using methotrexate, which were conducted by GPs and practice managers at two practices in the UK. An additional patient was recruited through their consultant, in a similar manner. Patients were approached by letter from their GP/consultant, which included an information sheet which explained the details of the study. Patients replied to the researchers if they wished to take part. Primary Care Trust (community healthcare) R\&D approval was obtained for the research with patients. NHS Trust R\&D approval and honorary research contracts were obtained for the research with NHS professionals. All participants provided their consent before interviews or observations began.

Questions were developed by consulting a range of literature, including government and company reports, journal articles and web sites. These provided an indication of the types of problems that were likely to occur, although questions remained sufficiently open to identify other areas of need, in addition. The semi-structured interviews with patients covered patient demographic details, a review of the types of medication they were taking, details of their use of medicines (including their history of taking methotrexate) and any problems they might have experienced, both when first prescribed methotrexate and more recently.

The interviews with healthcare professionals were concerned with the nature and frequency of problems associated with methotrexate in the healthcare system, and the structure of this system. Healthcare professionals were identified through opportunity and snowball sampling. 17 interviews and discussions were conducted individually with 10 healthcare professionals, working in different areas of the NHS. Given the size of the study and the variability in NHS practice (HMSO, 2000), the exercise was intended to highlight local working practice, and to act as a first step towards understanding methotrexate use in the UK.
In addition, the physical ("reach \& stretch", “dexterity" and "seeing") and cognitive ("thinking") capabilities of patients were assessed against capability scales developed by Martin et al. (Martin et al., 1988). To do this, patients were read descriptions of tasks requiring various levels of cognitive or physical ability (e.g. "cannot count well enough to handle money" and "has difficulty wringing out light washing or using a pair of scissors") and were asked to agree or disagree whether each was an accurate description of their level of ability.

\subsection{Observations}

Observations were used to clarify and supplement the data collected in the interviews. Patients were observed as they used (opened and closed packages, extracted and picked up tablets) a variety of different types of packaging, including:

- A bottle with an "easy" push-down- $\&$-turn CRC (approximate dimensions: top diameter $=28 \mathrm{~mm}$, ribbed gripping section on top $=16 \mathrm{~mm}$ tall, bottle diameter $=32 \mathrm{~mm}$, bottle height $=48 \mathrm{~mm}$; requiring an approximate $2 \mathrm{~kg}$ "push-down" force and $0.5 \mathrm{Nm}$ torque to open).

- A bottle with a "difficult" push-down-\&-turn CRC (approximate dimensions: top diameter $=28 \mathrm{~mm}$, ribbed gripping section on top $=16 \mathrm{~mm}$ tall, square-shaped bottle base $=33 \mathrm{~mm}$ $\times 27 \mathrm{~mm}$, bottle height $=48 \mathrm{~mm}$; requiring an approximate $3 \mathrm{~kg}$ "push-down" force and $1 \mathrm{Nm}$ torque to open).

- A blister pack, containing three blister strips and an information leaflet, tightly packed in a box, as provided by the manufacturer.

- A bottle with a double-walled squeeze \& turn closure.

Both the CRCs were typical of those provided by community and hospital pharmacies in the UK. Given the cytotoxic nature of methotrexate tablets, and the dangers of overdose, patients were presented with blister packs containing low-risk tablets such as vitamins and homeopathic medicines, after review by a pharmacist.

The difficulty of opening the bottles with a push-down-\&-turn CRC was assessed through recording comments from patients who were asked to "think aloud" during the exercise. In addition, through analysis of the videos, the first author measured the length of time it took for patients to open these containers. Patients were first allowed to familiarise themselves with the container, and the timing was taken from the moment the patient first applied a pushing or turning motion to the CRC until it was separated from the neck of the bottle.

\subsection{Process mapping and risk analysis}

Through the interviews with healthcare professionals and through perusal of a number of shared-care protocols, two maps

Table 1

Characteristics of the interviews with patients and healthcare professionals.

\begin{tabular}{|c|c|c|}
\hline Interviewee & No. of interviewees & Type of interview \\
\hline Patient & 12 & $\begin{array}{l}11 \text { face-to-face semi-structured interviews ( } 11 \text { patients) } \\
1 \text { telephone semi-structured interview, for patient's personal reasons ( } 1 \text { patient) }\end{array}$ \\
\hline General Practitioner & 1 & 5 face-to-face unstructured interviews ( 1 GP five times) \\
\hline Community pharmacist & 2 & $\begin{array}{l}2 \text { face-to-face unstructured interviews ( } 2 \text { pharmacists) } \\
1 \text { brief discussion ( } 1 \text { pharmacist, as a follow-up interview) }\end{array}$ \\
\hline Hospital pharmacist & 3 (at 2 hospitals) & $\begin{array}{l}2 \text { face-to-face unstructured interviews ( } 2 \text { pharmacists) } \\
1 \text { telephone unstructured interview ( } 1 \text { pharmacist) }\end{array}$ \\
\hline Specialist nurse & 2 (at 2 hospitals) & $\begin{array}{l}1 \text { face-to-face unstructured interview ( } 1 \text { nurse) } \\
1 \text { telephone unstructured interview ( } 1 \text { nurse) }\end{array}$ \\
\hline Clinical directors & 2 ( 1 at 1 hospital and 1 at NHS regional level) & $\begin{array}{l}3 \text { face-to-face unstructured interviews ( } 1 \text { director three times) } \\
1 \text { telephone unstructured interview ( } 1 \text { director) }\end{array}$ \\
\hline
\end{tabular}


were developed of the healthcare system regarding methotrexate. The maps were reviewed by a GP and a hospital-based clinical director (who was also a practising pharmacist). Modifications were made to the maps until agreement was reached on the completeness and accuracy of their content. Subsequently, the maps were used to form the main input to two risk analysis sessions, involving the same healthcare professionals, to identify the areas of the healthcare system that provided the greatest concern in the safe use of methotrexate. These participants were selected due to their complementary knowledge of different sectors of the healthcare system, their considerable experience of working in the NHS (and in particular their exposure to methotrexate-related problems in their respective workplaces) and their willingness to provide several hours of their time.

Two differing risk analysis methods were chosen to maximise the chances of identifying risks. The first analysis consisted of a HAZOP study. A typical HAZOP study is described below:

1) It is common to start with a description of the system in the form of a process map, showing its intended functions. The chemical production industries, where HAZOP has been used traditionally, often use "piping and instrumentation" diagrams, which show the interconnections of equipment. In a traditional HAZOP, each function is analysed in turn, in order to provide input to what tends to be a very systematic and comprehensive analysis.

2) Deviations from each function are considered by applying one or more "guide words" to each function. Guide words such as "No", "Less", "More" and "Other" can be applied, to determine how each function might deviate - i.e. to identify possible failures in the system. If the deviation is meaningful, then this is recorded. For example, considering the flow of a chemical, a potential deviation from the norm would be "More" chemical. Another might be "Other" chemical.

3) The consequences, causes and any suggested actions for each deviation are recorded. Each type of deviation can be given a risk score and can then be used to judge whether the system offers a satisfactory level of risk, or help to prioritise this suggested action. The risk score (Risk Priority Number - RPN) can be calculated by taking the product of thee risk components: the likelihood (L), impact (I) and detectability (D) (ease of detection) of each deviation.

In the case of the methotrexate HAZOP, the two process maps depicted the intended functions, as described in Step 1. The RPNs were calculated from a simple three point scale for each risk component $(1=$ low, 2 =medium, 3 =high for Likelihood and Impact; with reverse scoring for Detectability since it is a desirable rather than undesirable characteristic), since the healthcare professionals felt that it was difficult to define precise values.

A HAZOP study was deemed to be a suitable risk analysis method because the process maps considered flows of materials and information in a similar way to the flows of chemicals or materials in the process industries, and the purpose of the analysis was to investigate how the system might fail to perform as intended. The HAZOP provided the opportunity to assess the process in a systematic fashion, through structured thinking by using guide words, and how the system might introduce errors.

After the HAZOP study was conducted, the research team re-reviewed the results from the interviews and observations with patients, the interviews with healthcare practitioners and the process maps. By considering each setting in healthcare in turn (e.g. home, GP practice, etc) and brainstorming for risky situations, a number of "risky scenarios" were identified by the research team, in the form of a "risky scenarios study". The outputs from the HAZOP study were also added to the list of risky scenarios.

Next, a second risk analysis meeting was arranged with the healthcare professionals, for them to assess the risk of each scenario. In this case the same three risk components were scored for each risky scenario, taking the likelihood of occurrence of the scenario, the severity of harm and the ease of detecting the failure. Lastly, an RPN was calculated.

This was different from the HAZOP, in that it was led by location of treatment and was conducted through a free-form analysis of failure modes, rather than relying directly on the structure of a diagram. It was anticipated that the combination of the rigour of a HAZOP and the more free-form structure of the risky scenarios study would be complementary.

\subsection{Design exclusion assessment}

Design exclusion occurs when choices made in the process of designing a product result in a design which cannot be used effectively. Given the anticipated problems that users of methotrexate would experience, a design exclusion assessment was therefore carried out.

Quantitative design exclusion assessment, as described by Clarkson et al. (Clarkson et al., 2003), focuses on evaluating the number of people who are likely to experience difficulties in using a product. The first step in examining any interaction is to expand the use scenario (i.e. the process of use within a given context) into its component tasks to enable a systematic assessment to be performed. As with all studies of this type, there are many possible interaction paths, so assumptions have to be made about the context of use. For example, it was assumed for this study that the methotrexate to be used was stored in a location that was easy to reach, and so the patients' abilities to reach and stretch were not assessed. Similarly, it is assumed that a use scenario, such as using a standard bottle with a CRC, requires a specific number of tasks. To use medication in a standard bottle with a CRC, for example, the patient must read and understand instructions, open a CRC and pick up a small tablet.

In summary, the demands made by the product on the user for each task are estimated. The number of people unable to meet such demands are then evaluated, where the demands are expressed in terms of the user capability required to interact with the product, according to scales developed by Martin et al. (Martin et al., 1988) and adapted for use in product assessments by Clarkson et al. (Clarkson et al., 2007). The total number of people excluded from the interaction can be estimated by taking the maximum demands made by the product during the complete interaction. The levels of exclusion are calculated from the Office of National Statistics (ONS) 1996/7 Disability Follow-up to the Family Resources Survey (Grundy et al., 1999; Semmence et al., 1998).

\subsection{Developing design requirements and concepts}

Design requirements were developed by the researchers through a review of the nature and frequency of problems experienced by patients and practitioners in the healthcare system. As these requirements were to be used by professional designers to develop concept designs, a brief list was produced to encourage broad-ranging designs and to ensure that the participants in the design workshop were not overloaded.

Subsequently, using the requirements, design "concepts", were developed through a workshop, whose members included those from various backgrounds such as general engineering design, healthcare engineering design, packaging design and marketing. 
Several days before the workshop began, designers were sent a briefing sheet, which outlined the background of the research and the objectives of the study. All participants read the sheet. The workshop began with a short presentation, which again outlined the background of the project and highlighted the key problems identified during the research, including the healthcare systemrelated observations and those directly related to medicines packaging and labelling. To encourage further thought about the design problem, the designers were asked to develop their own design requirements based on what they had learned through the presentation. With a view to assisting future design changes, the findings from the research, showing the problems that patients and stakeholders experienced, were presented to the manufacturers of methotrexate in the UK. Videos, photographs, quotations and explanation from the researchers were used to highlight these difficulties.

\section{Results}

\subsection{Interviews with patients}

Five patients at one GP practice agreed to take part in the study and six at the other. An additional patient was recruited through their consultant at their local hospital; giving a total of 12 patients (11 female, 1 male), aged 59.8 years on average (range 17-82; standard deviation 19.2). Nine out of the 12 patients had rheumatoid arthritis, two had psoriatic arthritis and one had another medical condition. Patients assessed against the ONS data were found to experience few major problems in any of the categories of physical strength, dexterity, visual ability or cognitive ability.

The review of patients' medicines showed that they were taking regularly on average 7.7 prescription-only medicines (range 2-13; standard deviation 4.2). Five patients took 10 or more prescription-only medicines. At the time of contact with the researchers, approximately half of the patients had their methotrexate delivered in bottles with CRCs and half in blister packs, although patients explained that the container often varied from one type to the other. Patients also highlighted the fact that the appearance of the container varies, according to the pharmacist they attend, and from one purchase of their medicine to another. There was a wide variation in how long the patients had been taking methotrexate, ranging from four months to 20 years, with an average of 6 years.

Three of the patients had assistance in preparing/taking their medicines, either from a friend or spouse. One of the key reasons given for this was that their assistant was judged by them to be better at opening the medicines containers.

When examining the patients' medicines containers, a number of observations were made. Blister strips can appear similar or even identical to those from other manufacturers, which may contain different medicines, particularly when viewed from the opposite side to the foil wrap, which is often unmarked and made of an opaque, white plastic. In addition, it is fairly routine for pharmacists to re-pack blister strips from a manufacturer's blister pack into a white generic pharmacy box. Many different medicines may be issued to patients in such boxes, as illustrated in Fig. 1, and the labels on the boxes can also appear similar at a glance.

Several issues were noted with pharmacy bottles in relation to their appearance. Firstly, such bottles can be round, rectangular or square in cross-section. This means that, when viewed from the front of the bottle, important information can be hidden due to the way in which the label is wrapped around the sides of the container. Secondly, particularly on smaller bottles, labels can be misaligned or too large for the bottle and consequently distorted so that information is difficult to read, as illustrated in Fig. 2, where the word "METHOTREXATE" and the reference to the strength of each tablet have been distorted. Thirdly, as with blister packs, medicines may be repacked into generic pharmacy bottles, and the containers can appear similar to each other, as shown in Fig. 1.

Continuing the theme of similarity of packaging, almost all of the patients were prescribed folic acid as well as methotrexate. Folic acid and methotrexate tablets are similar in appearance, as illustrated in Fig. 3.

To examine actual practice, patients were asked whether they had mixed up their medicines in the past. Although most patients felt this would be difficult, three had done so; two with methotrexate and folic acid. One of the patients had reached the stage of ingesting the wrong tablets, on one occasion. Three patients commented, without prompting, on the similarity between methotrexate and folic acid containers and tablets.

Given the significant number of medicines that patients were receiving, it was common for patients to store all their medicines together in a single container, such as an ice-cream tub or shoe box, as shown in Fig. 4.

Patients were also asked whether they stored their medicines in the original containers. Three patients transferred their methotrexate tablets into another container because the original was awkward or too difficult to open. For example, upon receiving a new bottle or blister pack from the pharmacy, one patient would remove all tablets in "one session" and place them in an old methotrexate bottle with a CRC. The interviewee reported that the old methotrexate CRC (some seven years old) was much easier to open, as the CRC had become very worn over the years.

Seven of the patients expressed concern over the difficulties they experienced when opening bottles with push-down-and-turn CRCs. Patients experienced pain and/or frustration when opening containers, as illustrated by the following quotations from three different patients:

"[It's] physically [painful], just twisting it in your fingers." "Some are really a nightmare. The new ones are a nightmare." "When I had the bottles I could hardly ever, ever, ever open them because of the lock on them when you have to press down and turn. To me it just seemed completely bizarre why you'd give someone with arthritis a bottle that is really hard to open. It's kind of like saying: 'here's your medication... if you can get to it!'."

Although all patients said they were able to use blister packs, many found them awkward or "tedious" to use, especially if they had many tablets to extract. The following quotations are indicative of the problems patients experienced:

"I find blister packs tedious. They're slightly easier than screw caps. But when you have to take six, it's fairly tedious pressing out six pills."

"I must admit that some of the blister packs are really difficult to get the tablets out of."

"It's a bit annoying pushing the pills through because it's a bit fiddly."

As a result of their difficulties in using medicines containers, patients explained that they adopted a variety of coping strategies, including:

- Using scissors to cut the blister foil to ease removal of the tablets from the blister strips.

- Transferring tablets from one container to another that was easier to open.

- Using tools such as nutcrackers or jam jar grips to open bottles with CRCs. 


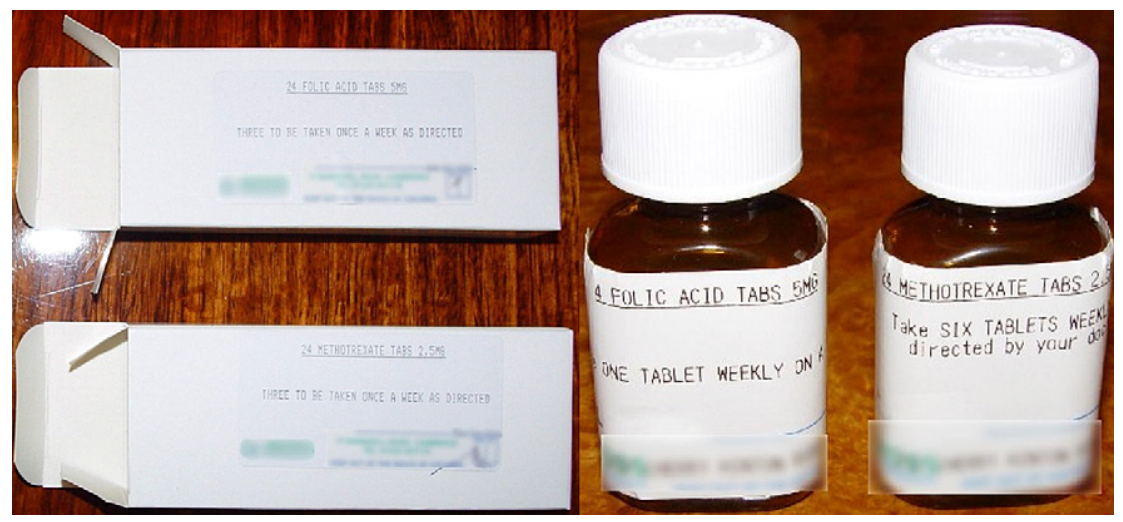

Fig. 1. At a glance, pharmacy containers can appear similar (patient details have been removed and company details have been blurred).

- Not fully re-closing the CRC, to ensure that it was opened more easily the next time it was used (three patients), meaning that its purpose was defeated.

In addition, through the interviews, the researchers identified a number of areas in the healthcare system as having the potential to compromise patient care:

- A lack of information provided to patients by various parties, including pharmacists (who may not provide information leaflets to patients because the manufacturer does not provide them with a sufficient number, and copying is not allowed) or other healthcare professionals (for example, the supply of information sheets about methotrexate use for arthritis patients was sporadic).

- Conflicting dosing information being registered in different locations (e.g. on a patient's records at the GP's practice, at their local pharmacy, at hospital and the labelling on the patient's medication), often due to the frequency with which the patient's dose will change, particularly when early in their treatment when the most appropriate dose is being determined through monitoring and re-prescribing.

- Due to the quantity of tablets supplied, some patients may only rarely need to attend the surgery/pharmacy, meaning that the opportunity for a healthcare professional to identify any dosing error presents itself infrequently.

- There are many areas where the blood monitoring process can fail to identify improper methotrexate dosing (e.g. failure to be

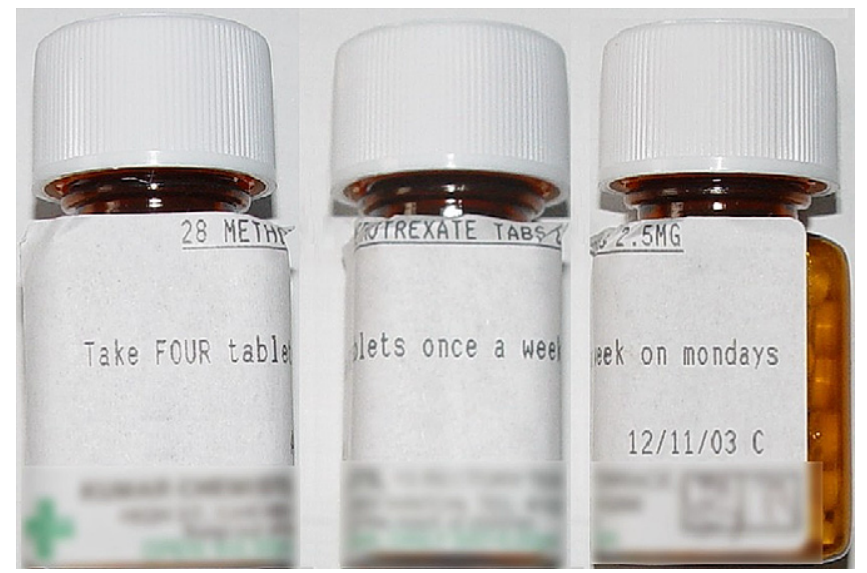

Fig. 2. The arrangement of labelling around the sides of the container (patient details have been removed and company details have been blurred). issued with appropriate literature to record key information such as methotrexate dose and next appointment times, failure by the patient to attend appointments for monitoring and failures in taking prompt action as a result of adverse effects being discovered through blood testing).

\subsection{Observations of patients}

All of the 11 patients who were interviewed in their homes agreed to be videotaped as they opened the containers. The observations complemented the results from the interviews since they allowed the researchers to see at first hand the scale and nature of the difficulties that patients experienced, and the various strategies they used to try to open the containers, including using tools, table tops to provide support and different hand gripping arrangements. The results from the difficulty assessment of patients opening bottles with CRCs are tabulated in Table 2, with added salient comments from the patients.

The observations added weight to the results from the interviews: opening the bottles with CRCs presented a significant challenge to the patients, with nearly half of the patients being unable or unwilling to open the container with the "difficult" CRC.

The 11 patients were also observed as they opened blister packs and handled tablets. The use of blister packs requires a number of sub-tasks to be performed, and observations from each of these are described in Table 3.

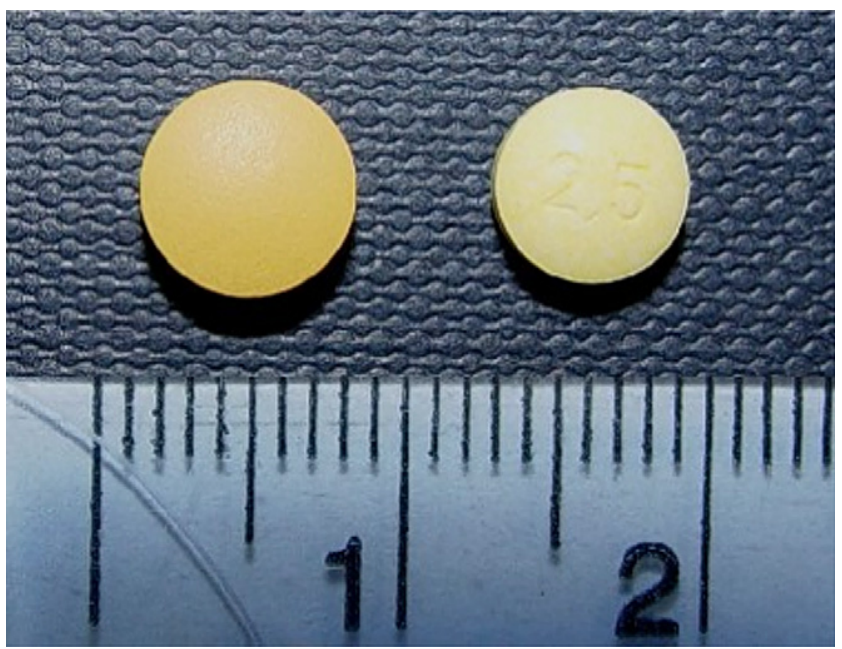

Fig. 3. Folic acid (left) and methotrexate (right) tablets (scale in $\mathrm{cm}$ ). 


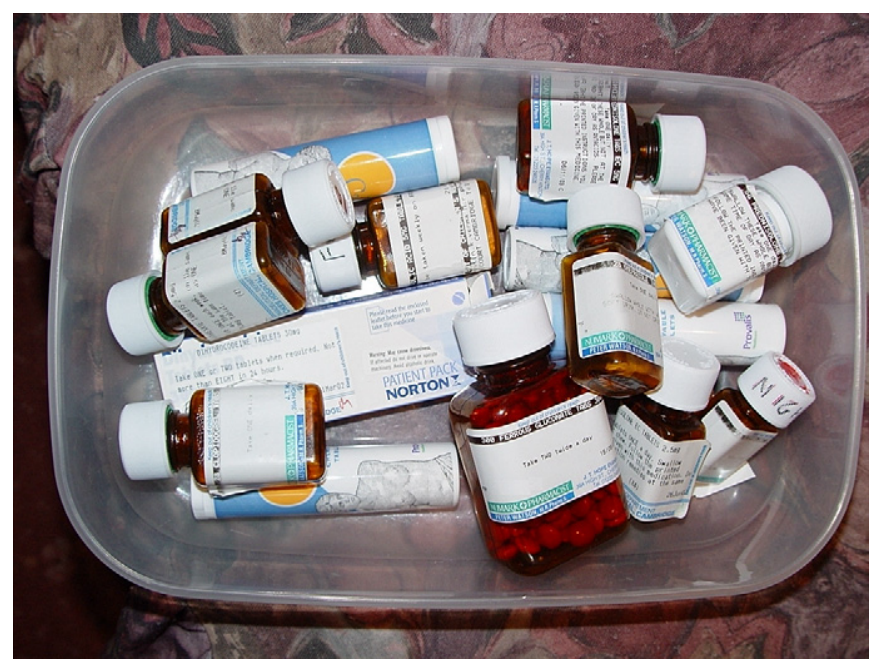

Fig. 4. A typical storage method for patients using multiple medicines.

To further investigate their ability to use medicines, the patients were asked to pick up a small tablet, which was spherical in shape and approximately $3 \mathrm{~mm}$ in diameter. Two patients had difficulty with this task. In at least one case, the problems might be explained by the patient's medical condition, which made it difficult to form a fist-shape, which is necessary to pick up the tablet.

Table 2

Results of assessment of patients opening bottles with CRCs $(n=11)$.

\begin{tabular}{|c|c|c|c|}
\hline $\begin{array}{l}\text { Patient } \\
\text { ID No. }\end{array}$ & $\begin{array}{l}\text { Time to taken to } \\
\text { remove CRC from } \\
\text { bottle with "easy" } \\
\text { CRC }(\mathrm{s}) . \mathrm{X}=\text { did not } \\
\text { wish to attempt. } \\
\mathrm{N}=\text { attempted but } \\
\text { could not open } \\
\text { container. }\end{array}$ & $\begin{array}{l}\text { Time to taken to } \\
\text { remove CRC from bottle } \\
\text { with "difficult" CRC (s). } \\
\mathrm{X}=\text { did not wish to } \\
\text { attempt. } \mathrm{N}=\text { attempted } \\
\text { but could not open } \\
\text { container. }\end{array}$ & Patient's comments \\
\hline 1 & 6 & 14 & $\begin{array}{l}\text { “Quite a struggle” } \\
\text { (difficult container) }\end{array}$ \\
\hline 2 & $\mathrm{~N}$ & $\mathrm{X}$ & $\begin{array}{l}\text { "No I can't do it... } \\
\text { there's not enough } \\
\text { power in my hands" } \\
\text { (easy container) }\end{array}$ \\
\hline 3 & 3 & 5 & - \\
\hline 4 & 10 & 13 & $\begin{array}{l}\text { "It hurts my fingers" } \\
\text { (difficult container) }\end{array}$ \\
\hline 5 & 24 & $\mathrm{~N}$ & $\begin{array}{l}\text { "I'd have to get help } \\
\text { on that one" (difficult } \\
\text { container) }\end{array}$ \\
\hline 6 & $\mathrm{~N}$ & $\mathrm{X}$ & $\begin{array}{l}\text { “No, I couldn't do it” } \\
\text { (easy container) }\end{array}$ \\
\hline 7 & 7 & $\mathrm{~N}$ & $\begin{array}{l}\text { "It really is child- } \\
\text { proof and age-proof" } \\
\text { (difficult container) }\end{array}$ \\
\hline 8 & 3 & 19 & $\begin{array}{l}\text { "Oh gosh... That was } \\
\text { quite a difficult one" } \\
\text { (difficult container) }\end{array}$ \\
\hline 9 & $\mathrm{~N}$ & $\mathrm{X}$ & $\begin{array}{l}\text { "No, too difficult" } \\
\text { (easy container) }\end{array}$ \\
\hline 10 & 5 & 5 & $\begin{array}{l}\text { "Ones like these I } \\
\text { really have to press } \\
\text { down..." (easy } \\
\text { container) }\end{array}$ \\
\hline 11 & 18 & 2 & $\begin{array}{l}\text { "It's very hard." (easy } \\
\text { container) }\end{array}$ \\
\hline Totals & $\begin{array}{l}3 \text { patients unable to } \\
\text { open "easy" } \\
\text { container. Average } \\
\text { opening time }=10 \mathrm{~s} .\end{array}$ & $\begin{array}{l}5 \text { patients unable/ } \\
\text { unwilling to open } \\
\text { “difficult" container. } \\
\text { Average opening } \\
\text { time }=10 \mathrm{~s} \text {. }\end{array}$ & \\
\hline
\end{tabular}

In assessing the ease of opening of the double-walled squeeze \& turn closure, patients experienced difficulties in both identifying how to open the container and in opening it. Ten patients attempted the task (one declined since she believed it would be too difficult for her). The majority had not attempted to open such a container before. Seven out of the ten patients took over a minute in their attempt to open this CRC and much of this time was generally spent in fruitlessly attempting to turn the top without first squeezing the ends. Two patients took nearly three minutes each to open the closure. One succeeded and the other gave up after this period of time. Three patients commented that it was difficult to notice or read the instructions since they were embossed on the closure and no attempt had been made by the manufacturer to use contrasting colours.

Once they had identified how to open the container, four patients were unable to provide sufficient force to squeeze the top to release the child-resistant mechanism and hence were unable to remove the closure.

\subsection{Interviews with healthcare professionals}

The interviews highlighted a number of potentially problematic areas in the NHS where safety of patients may be compromised under particular circumstances. These included:

- Significant delays in communications between hospital and community care.

- Critical information being lost between different nodes in the healthcare system, e.g. between practice receptionists and GPs or between GPs and the practice nurse.

- Different healthcare professionals working at different times, meaning that direct communication between them can be problematic, particularly at weekends.

- Incorrect information being passed between healthcare professionals (including an example of a GP being informed by a consultant that methotrexate should be taken once a day, not once a week).

- A lack of availability of the procedures concerning giving methotrexate in an NHS hospital, leading to the potential for healthcare professionals to be under-informed.

- Through contact with specialist nurses, further examples of patients' errors in taking methotrexate, including several cases where patients had taken four times the correct dose, due to mix-ups between the $10 \mathrm{mg}$ tablets and the $2.5 \mathrm{mg}$ tablets.

- The default setting on the GPs' prescribing software being a once-daily dose, meaning that it was not difficult to misprescribe methotrexate to rheumatology/dermatology patients at a lethal frequency.

\subsection{Process mapping and risk analysis}

Both process maps showed various job types and entities connected with the provision and management of methotrexate, ranging from GPs and consultants to blood test results and databases containing patient-related information. Each was connected by arrows depicting flows of information and materials between the different stakeholders.

The first map is shown in Fig. 5, which is based on an amalgamation of different shared-care arrangements from around the UK and therefore shows a variety of ways in which care can be provided. For example, whilst a GP might normally be informed to prescribe methotrexate by a consultant, on occasion the consultant might prescribe methotrexate directly. Given the size of the study, however, this should not be considered to be an exhaustive representation of the arrangements across the NHS, and has been included as an illustration in particular to help the reader 
Table 3

Observations on patients' difficulties and coping strategies when accessing medicines from a blister pack $(n=11)$.

\begin{tabular}{|c|c|}
\hline Sub-task & Observations \\
\hline Opening box & No difficulties for patients \\
\hline Removing blister strips & Three experienced difficulties. One patient shook the box until a strip was sufficiently exposed to be pulled out with a finger and thumb. \\
\hline Pushing out tablets & $\begin{array}{l}\text { Three experienced difficulties. Two pierced the foil on the back of the blister strip with a fingernail to facilitate removal of the tablets. One } \\
\text { patient took } 15 \text { seconds to remove a single tablet. }\end{array}$ \\
\hline $\begin{array}{l}\text { Replacing contents } \\
\text { back in box }\end{array}$ & $\begin{array}{l}\text { Five experienced difficulties. Replacing the contents was found to be more difficult when fewer tablets were present in the strips: in such } \\
\text { cases the strips were more flexible and were sometimes misshapen due to wear and tear, meaning that more precise manipulation was } \\
\text { required to return them into the box. Patients' ease of replacing the contents was also affected greatly by the method that they employed. } \\
\text { Some patients assembled the contents outside the box and then replaced them all at once, whereas others returned the contents in } \\
\text { a piecemeal fashion, which appeared to be more problematic when space in the box was lacking. }\end{array}$ \\
\hline
\end{tabular}

appreciate the form of the two process maps. The second map is not displayed in this paper, since it was an extension of the first and contained similar content but at a greater level of detail; focusing on the blood test monitoring process.

The maps highlighted the complex and variable nature of the healthcare system that supports the delivery of methotrexate to patients, and showed many interactions between a range of stakeholders, and consequently suggested numerous areas where problems could occur.

For the HAZOP study, using the maps as prompts, the GP and clinical director identified a number of deviations from intended practice, and subsequently calculated a risk score for each.

Ideally, every link between the nodes would have been interrogated in turn with a pre-defined list of guide words. However, given the participants' time restrictions, it was not possible to analyse all links systematically, and participants selected links for consideration in the HAZOP study.

The HAZOP results produced a range of high, medium and low risks. High and medium risks included the danger that the patient's records (either a blood record card, medical record, prescribing record or drug chart) may not be updated when information is added or changed; that records may not be legible and that information provided to patients may be unclear, incorrect or incomplete. An excerpt from the HAZOP results is shown in Table 4.

Under the "Risky Scenarios" study, 47 scenarios were identified by the researchers, across a range of healthcare settings, including the GP practice, home, community and hospital pharmacies and hospital wards. The list was prepared in a tabular format and reviewed by the clinical director (the GP was unavailable) and a risk score (RPN) was added to each scenario. The top five risky scenarios are shown in Table 5 .

A complete set of risk analysis results is presented by Ward et al. (Ward et al., 2004).

\subsection{Design exclusion assessment}

The abilities of the patients were assessed, in terms of (1) reach and stretch, (2) dexterity, (3) seeing and (4) intelligent functioning.

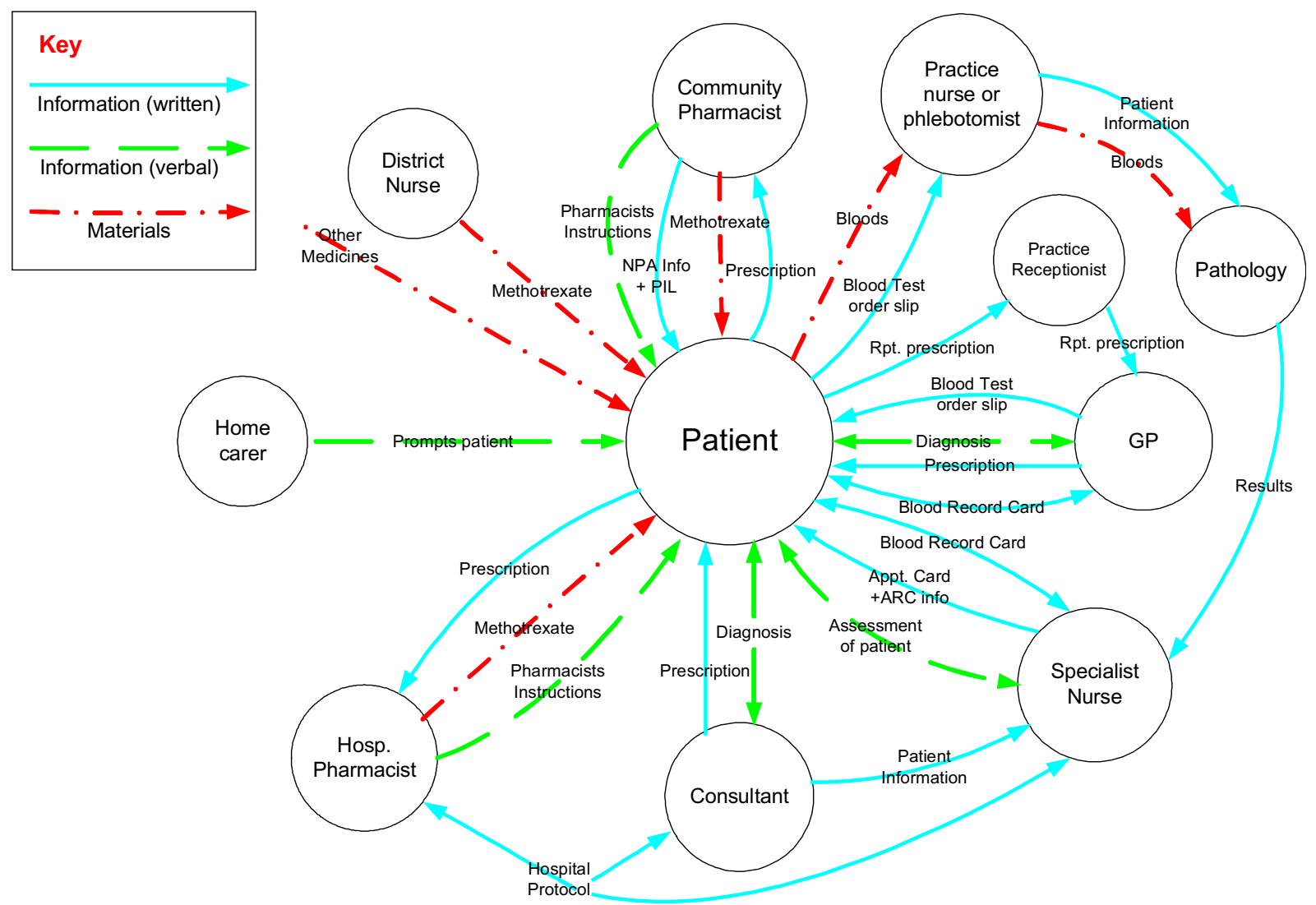

Fig. 5. Shared-care arrangements for methotrexate supply in the NHS. 
Table 4

An excerpt from the HAZOP results.

\begin{tabular}{|c|c|c|c|c|}
\hline Function & Deviation & $\begin{array}{l}\text { Risk } \\
\text { component }\end{array}$ & Result & Comments - causes and consequences \\
\hline \multirow[t]{4}{*}{$\begin{array}{l}\text { Provision of blood } \\
\text { record card }\end{array}$} & \multirow[t]{4}{*}{$\begin{array}{l}\text { Blood record } \\
\text { card out of date }\end{array}$} & $\mathrm{L}$ & 2 & $\begin{array}{l}\text { When attending a blood test, patients are expected to bring their blood record card with them. It may be } \\
\text { easy to forget to bring this card, hence it could easily become out of date. }\end{array}$ \\
\hline & & I & 2 & $\begin{array}{l}\text { Out of date cards can make it difficult for the nurse to identify what constitutes a normal blood test result } \\
\text { for that patient. Test results are a useful early warning system of the suitability of the patient's medication } \\
\text { practices. Failure to spot trends could lead to a deteriorating condition being missed. Impact of deviation } \\
\text { could be anything from low to high, depending on patient's dosing compliance. Average = medium. }\end{array}$ \\
\hline & & $\mathrm{D}$ & 1 & Patients are seen regularly, so good detectability. \\
\hline & & RPN & 4 & MEDIUM RISK \\
\hline
\end{tabular}

The results (Table 6) showed little variability across the patients, with all patients showing no or only a minor degree of impairment.

Table 7 summarises the results from the design exclusion assessment.

It is important to note that the levels of exclusion calculated for each of the use scenarios are based solely on users with functional impairments. They do not include users with learning difficulties, as they are not typically classified as disabled under the ONS definitions. As such, the estimated levels of exclusion can be considered to be conservative since the ONS data are based on self-reporting (which in itself is most often conservative) and represents only those living in private homes and with functional impairments. Furthermore, it is likely that a higher proportion of methotrexate patients would be excluded from using packaging, since they are likely to have more severe strength and dexterity problems than those in the general data from which the results were derived.

\section{Discussion}

For both sets of interviews, and the observations with patients, a degree of caution is needed in interpreting the results. The research was carried out approximately four years after a major incident involving inadvertent methotrexate overdose that had occurred in the same geographical area. The report that followed this incident (CHA, 2000) strongly influenced local practice towards methotrexate across community and hospital-based care. As such, it is possible that practice was better in this area than in others less local to this incident. Given the limited sample size, the degree to which the results can be generalised to the wider population of methotrexate users is also restricted.

Regarding the assessment of strength-related functions (e.g. opening CRCs), the severity of difficulties experienced by users in this study may be greater than those for the average user of methotrexate, particularly given the fact that almost all of the participants were females, who have been found to be nearly twice as likely than males to be unable to open containers (Atkin et al., 1994).

Nevertheless, despite their high level of competence (as assessed against the ONS data), patients experienced a number of problems, which can broadly be divided into two types of difficulty.

\subsection{Difficulties associated with correct identification}

Various problems were identified which relate to correct identification of medicines. The similarity in appearance between containers of different medicines, and methotrexate and folic acid tablets, could lead to mix-ups between medicines. With two of the 12 patients actually confusing methotrexate with folic acid (both patients were experienced users since both had each been taking methotrexate for several years without interruption), the study suggests that mix-ups may not be uncommon amongst the wider population of methotrexate users. Due to their similarity in size, colour and shape, it is perhaps particularly unfortunate that methotrexate and folic acid tablets - as they are designed currently - are both typically used in conjunction with each other. Through additional studies, further clarification would be beneficial on the scale of mix-ups between a broader set of medicines due to similarity of appearance, to determine whether it would be helpful to patients and other stakeholders to change the design of either methotrexate or folic acid tablets and/or packaging or combinations of other medicines.

The researchers are not aware of published evidence to confirm or deny an increased risk of mix-ups between medicines as a result of concurrent use of many different drugs. Nevertheless, with an average of approximately eight prescription-only medicines, it is possible that the risk of mix-ups was increased for the patients in this study. It seems logical that the storage of all medicines together in a single container may also contribute to the risk, although there appears to be a similar lack of evidence in the wider literature to support or refute this.

Table 5

An excerpt from the risky scenarios study results.

\begin{tabular}{|c|c|c|c|c|}
\hline Scenario & $\mathrm{L}$ & I & $\mathrm{D}$ & RPN \\
\hline $\begin{array}{l}\text { 1. (At Home) Wrong dose administered (e.g. if } 10 \mathrm{mg} \text { tablet is used instead of } 2.5 \mathrm{mg} \text { tablet). This may happen for example when the number of } \\
\text { tablets (e.g. } 15 \mathrm{mg}=6 \times 2.5 \mathrm{mg} \text { ) is changed (e.g. } 15 \mathrm{mg}=1 \times 10 \mathrm{mg}+2 \times 2.5 \mathrm{mg} \text { ) and the patient becomes confused between the } 2.5 \mathrm{mg} \text { and } \\
\text { the } 10 \mathrm{mg} \text { tablets (e.g. takes } 6 \times 10 \mathrm{mg} \text { ). }\end{array}$ & 3 & 3 & 3 & 9 \\
\hline $\begin{array}{l}\text { 2. (At Home) Folic Acid (FA) vs. Methotrexate (M) - similarity in FA and M packaging and/or appearance of FA and M tablet and confusion results, } \\
\text { leading to the ingestion of the wrong number of tablets. }\end{array}$ & 3 & 3 & 3 & 9 \\
\hline $\begin{array}{l}\text { 3. (In Community Pharmacy) Pharmacy picking error - e.g. Methotrexate } 2.5 \mathrm{mg} \text { stored next to Methotrexate } 10 \mathrm{mg} \text { and wrong tablets are dispensed, } \\
\text { leading to potential for } 4 \mathrm{x} \text { overdose (would probably only occur with bottle confusion). }\end{array}$ & 3 & 3 & 1 & 9 \\
\hline $\begin{array}{l}\text { 4. (In Community Pharmacy) Pharmacist only writes total dose of Methotrexate, not number of tablets to take, which could lead to an overdose if the } \\
\text { strength of the tablets has changed. }\end{array}$ & 3 & 3 & 1 & 9 \\
\hline $\begin{array}{l}\text { 5. (At GP Practice) GP/receptionist fails to notice changed prescription request from patient (e.g. patient writes on the prescription request that the } \\
\text { dose has changed perhaps after seeing the specialist at the hospital, but GP authorises old prescription as he/she doesn't see the note). Could } \\
\text { result in too high a dose being taken if patient's dose is needed to be lowered. }\end{array}$ & 2 & 3 & 1 & 6 \\
\hline
\end{tabular}


Table 6

A summary of the assessment of patients' abilities.

\begin{tabular}{|c|c|c|}
\hline Assessment & Average result & $\begin{array}{l}\text { Standard } \\
\text { deviation }\end{array}$ \\
\hline $\begin{array}{l}\text { Reach and stretch (maximum possible } \\
\text { impairment score }=9.5 \text { ) }\end{array}$ & $\begin{array}{l}1.0 \text { (equivalent to having difficulty in putting one arm behind back to put on jacket/or putting one arm } \\
\text { out in front or up to head) }\end{array}$ & 1.7 \\
\hline $\begin{array}{l}\text { Dexterity (maximum possible impairment } \\
\quad \text { score }=10.5 \text { ) }\end{array}$ & $\begin{array}{l}0.9 \text { (equivalent to having difficulty picking up a small object such as a safety pin with one hand/being } \\
\text { unable to carry a pint of milk with one hand/having difficulty in tying bow in laces or string) }\end{array}$ & 1.0 \\
\hline $\begin{array}{l}\text { Seeing (maximum possible impairment } \\
\quad \text { score }=12.0 \text { ) }\end{array}$ & 0.2 (equivalent to full ability) & 0.4 \\
\hline $\begin{array}{l}\text { Intelligence (maximum possible } \\
\text { impairment score }=13.0 \text { ) }\end{array}$ & 0.0 (equivalent to full ability) & 0.2 \\
\hline
\end{tabular}

Whilst there appears to be general agreement in the NHS that there can be no substitute for reading the label (DH, 2004; MCA, 2003), users of medicines may find other design features to be helpful when selecting medicines, such as the judicious use of colour, as recommended in the Medicines and Healthcare Products Regulatory Agency's document, Best practice guidance on the labelling and packaging of medicines (MCA, 2003). The research in this paper also suggests that clear instructions should be provided by the manufacturer on how to open the container, as demonstrated by the problems experienced by patients who attempted to open the double-walled squeeze \& turn closure.

\subsection{Difficulties associated with ease of opening containers}

Given the length of time taken required to open their medicines containers and the proportion of methotrexate users who were unable to do this at all, it can be concluded that patients experienced sizeable difficulties when trying to access their medicines, whether packaged in blister packs or containers with CRCs. These problems frequently caused considerable frustration and, in some cases, notable pain. Underscoring this problem, several patients found it necessary to receive assistance in accessing their medicines. The design exclusion exercise provided further evidence of the scale of the problem that patients are likely to face when trying to access their medicines.

Nearly half of the methotrexate users were unable or were unwilling to attempt to open the more difficult of the two pushdown-\&-turn CRCs, and almost all patients commented without prompting by the researchers on the difficulty of using such containers. A similar proportion of users were unable to open the squeeze \& turn CRC. Although the problems with using blister packs were less severe (all patients eventually managed to extract the tablets) nearly half of the patients experienced at least a small degree of difficulty, which produced frustration and delay as they grappled with the packaging.

Table 7

Results of the design exclusion exercise (sub-tasks are denoted in italics).

\begin{tabular}{llc}
\hline Use scenario & $\begin{array}{l}\text { Percent of } \\
\text { people } \\
\text { excluded } \\
\text { aged 16+ }\end{array}$ & $\begin{array}{l}\text { Percent of } \\
\text { people } \\
\text { excluded } \\
\text { aged 75+ }\end{array}$ \\
\hline $\begin{array}{l}\text { Reading and understanding instructions } \\
\text { Picking up a small tablet }\end{array}$ & 2.6 & 6.5 \\
Opening a blister pack & 3.2 & 12.6 \\
Opening a bottle with a CRC & 2.7 & 9.3 \\
Using a blister pack (tasks = reading and & 6.5 & 20.3 \\
$\quad$ understanding instructions, opening blister & 6.3 & 22.7 \\
$\quad$ pack and picking up a small tablet) & & \\
$\quad \begin{array}{l}\text { Using a bottle with a CRC (tasks = reading and } \\
\quad \text { understanding instructions, opening bottle }\end{array}$ & 9.1 & 29.8 \\
$\quad$ with a CRC and picking up a small tablet) & & \\
\hline
\end{tabular}

The design exclusion assessments indicate that approximately 1 in 5 medicines users aged $75+$ are unable to open push-down\&-turn CRCs. This figure cannot easily be compared to the observed results with methotrexate users, due to the differences between the two populations (the study population consisted of a small sample of mostly female users of a younger average age, with specific medical conditions). However, both figures show that a significant proportion of users would be unable to access their medicines if using such containers. Whilst the level of exclusion for users of blister packs is predicted to be lower, it is still significant, and the design exclusion assessments do not show the considerable amount of effort needed to access medicines in such containers, as suggested by the observed results with methotrexate users.

The design exclusion assessments also show how the proportion of excluded users increases considerably when the variety of tasks necessary to use medicines are combined. The figures suggest that around one in four patients are unable to access their medicines, either in blister packs or in bottles with push-down\&-turn CRCs.

For blister pack use, the results indicate that it may be beneficial to educate the patient in suitable technique in replacing the medicine, since using the right technique can make this task considerably easier. Advice on suitable strategies might be given to patients by the manufacturer or other stakeholders such as pharmacists or specialist nurses. Alternatively, manufacturers could consider ensuring that there is sufficient room for all components within a blister pack (i.e. PIL and blister strips) to be inserted easily by patients with low dexterity. "Pill popping" devices, which can improve the ease of removal of tablets from blister packs, may also be of benefit to some patients (Mawle, 2003).

Risks to patients and possibly children may arise due to the "coping strategies" that patients developed as a result of these problems. Regarding the risk to patients, although no actual errors were identified during the interviews and observations, it is possible that they could take the wrong medicine due to the practice of transferring medicines from one container into another. Incorrect labelling on the new container could, for instance, result in confusion for a carer or healthcare professional if it became necessary, at some point in the future, to administer the tablets to the patient. Indeed, the researchers are aware of incidents when exactly this scenario has occurred after patients have been admitted into hospital, and care has been transferred to healthcare professionals who are unaware of the medicines repackaging.

Such a scenario may not be uncommon: since this research was completed, a study of 103 patients with inflammatory arthritis has been published (Hughes et al., 2008). The authors found that the majority of patients were unable to open their medicines containers without assistance from another person or a device used for opening containers. They also report a similar proportion of subjects ( 31 in 103 , versus 3 in 12 in this study) who routinely decanted their medicines from the original pack into other containers because of difficulties in opening. 
In Hughes' paper the authors examined the preferences of patients over seven different types of medicines container. The container of highest preference was squat-shaped, with a large diameter bottle and closure, which facilitated gripping and turning, and a wide neck which eased removal of the tablets. This may provides a useful indication on the shape and size of suitable containers of the future, particularly when considering the fact that the evaluation of a standard bottle (identical to that evaluated in this study) received the lowest preference score on account of the difficulty by patients in performing a push-down-and-turn movement.

Regarding the risks to children, several patients declared that they did not fully re-close the child-resistant tops, meaning that the purpose of the CRC was defeated. For patients, further problems could arise due to the potential of contamination in bottles that have been used for a very long period of time, or for single bottles that have contained a variety of medicines over the years.

\subsection{Other issues}

The study's findings, particularly through the results of the risk analyses, provide evidence that the healthcare system cannot be completely relied upon to support the safe use of methotrexate by patients. Since the packaging and labelling of medicines can also fulfil functions that the healthcare system is supposed to provide (e.g. providing clear dosing instructions), their design may be especially important in supporting safe healthcare, since patients may rely upon them even more than they might otherwise. For example, failures in the blood test monitoring process mean that it is even more important for patients to take the right dose of their methotrexate, through following the instructions on the labelling. Similarly, the frequent failure to provide PILs to patients means that the labelling may be the only source of information for patients, and hence is doubly important.

\section{Development of design concepts}

\subsection{Development of requirements}

Before asking the professional designers to develop design concepts, a number of design requirements were formed by the research team. Based on a review of the problems identified during the earlier stages of the research and the "five rights" of medicines use (right patient, right drug, right dose, right route, and right time), a very simple guiding principle was produced by the research team for the development of the requirements for methotrexate packaging and labelling:

Design concepts must help the patient to take the right dose of the right drug at the right time.

Based on the problematic areas identified, more specific design requirements were next developed by the research team:

1) Packaging and labelling concepts should ensure that the right dosing action is clear.

2) Packaging and labelling should be distinctive.

3) Packaging should be accessible, meaning that it should exclude as few users as possible.

At the design workshop, to encourage further thought about the design problem, the designers were asked to develop their own design requirements without researcher input, based on what they had learned through the presentation. Whilst the precise words were different, the designers produced requirements that were fundamentally identical to those above, a result which was judged as an independent vote of confidence in their suitability.

To avoid constraining ideas at this stage, and to ensure simplicity during the limited time available with the design consultants, a number of other design requirements were omitted from the brainstorming exercise. These included cost, child-resistance, maintaining tablet integrity and efficacy (including protection from light, heat and moisture), ensuring minimum handling of the tablet due to its cytotoxic nature and flexibility of supply due to the likelihood of dosing change.

\subsection{Development of design concepts}

The brainstorming session was divided into four sections: Tablet design, Packaging design, Labelling design and Potential Action by healthcare professionals/healthcare system-level design.

This process produced approximately 100 initial concepts (Ward et al., 2004). A review by the researchers, against the initial requirements and general constraints of practicality, reduced this list to a total of 36 design concepts, such as:

- Increase the size of methotrexate screw tops (to increase torque for opening).

- Provide patients with each week's dose in a separate container.

- Increase the size of methotrexate tablets to facilitate handling.

- Print on both sides of the blister strip.

- Provide only four weeks' supply of methotrexate for each prescription.

- Inform patients of the option to receive a standard closure.

The design company developed five further design concepts, as detailed below:

A. A distinctive shaped blister, linked to the tablet's shape. One week's prescription is dispensed from bulk at the pharmacy and added to a preformed blister container. The blister is sealed and labelled at the pharmacy. The label is tailored to meet individual patient needs.

B. One month's supply of tablets is stacked as four individual units, one for each week. Individual pots are filled and labelled at the pharmacy. Each pot can be filled with water, to assist the patient to take the dose.

C. Individual wallets are filled and labelled at the pharmacy. The label has a self adhesive peel-off strip which can be attached to a record card and returned to the pharmacy at the end of treatment. This has easy-open features, combined with a tamper-evident label.

D. A blister pack dispenser which dispenses and labels patientspecific prescriptions from a bulk reel of blisters. Packs are supplied in four parallel strips. Each strip provides one week's supply.

E. A reusable intelligent dispenser which alerts the patient to when the tablets need to be taken. Tablets are contained within a tamper proof carousel which is filled and labelled at the pharmacy. Bar code details are read by the dispenser. The patient depresses an actuator to deliver tablets, when the indicator light is illuminated. A safety interlock prevents the dispenser from being opened until the prescription is finished or prevents tablets being dispensed until a desired time interval has elapsed. Electronics within the dispenser store compliance information which can be later downloaded by a physician.

At the end of the research, the study's findings and the design concepts were presented by the researchers to the manufacturers 
of methotrexate. These were received with great interest. It was emphasised to the manufacturers that all concepts were yet to be evaluated formally and so must not be regarded as solutions.

\section{Developments since the research was completed}

Since the research was carried out, the UKs National Patient Safety Agency has produced a number of publications to improve the safe use of oral methotrexate across the healthcare system. These include the introduction of guidance on packaging design (NPSA, 2007a), aimed particularly at designers, and guidance for healthcare practitioners on good design practice for dispensed products (NPSA, 2007b), which also provides information on the availability of various aids to help patients use their medicines. At more of a "systems" level, the NPSA has also published guidance on the design of the dispensing environment in pharmacies (NPSA, 2007c).

Also at a systems level, the NPSA has published a package of measures (NPSA, 2006), which includes information for patients on safe practice with methotrexate, a blood monitoring and dosage record booklet for patients, guidance for practitioners and a requirements specification for the development of safer information technology systems. The authors believe that the combination of these measures address well the risks identified by this research. All NPSA's documents can be downloaded for free from their Web site.

From the perspective of the pharmaceutical industry, the shape of the $10 \mathrm{mg}$ tablet, which was originally very similar in appearance to the $2.5 \mathrm{mg}$ tablet, has been modified to aid discrimination between the two strengths, although controversy remains about the suitability of providing $10 \mathrm{mg}$ tablets at all and some healthcare regions in the UK do not prescribe these tablets as a matter of course.

Several manufacturers now supply methotrexate in the UK. Two notable changes since this study began are that at least one manufacturer now provides methotrexate in packs of 24 (consisting of two blister strips, each with two rows of six tablets), rather than the usual 28 tablets (also two blister strips, but with two rows of seven tablets). This may be to try to help distance the patient from the idea that seven tablets in a row might indicate one to be taken per day. Another manufacturer provides methotrexate in a small pot, very similar in size and shape to a camera film canister. However, most manufacturers provide bulk packs of 100 methotrexate tablets, for pharmacists to re-pack into generic pharmacy bottles, meaning that mix-ups may still occur between methotrexate and other medicines. The UK's National Patient Safety Agency continues to work with the pharmaceutical industry to develop safer and more user-friendly packaging.

\section{Conclusions}

Medication plays an increasingly important role in society, and its packaging and labelling provide a vital function in supporting safe use. Evidence from reports of medication errors has shown that poor packaging and labelling design results in a variety of problems to users of medicines, ranging from inconvenience to serious harm and even death. This study examines the use of methotrexate in tablet form and provides further, graphic evidence of these problems and an indication of their scale for users of methotrexate.

To help the findings from this work to be systems-based, the research investigated both methotrexate users' practice and the nature of the healthcare system which supports the use of methotrexate. The research also utilised a range of research methods. However, given the size of the study, the results - including the recommendations - need to be treated with caution. Further work is strongly recommended to clarify the scale and nature of problems experienced by patients using methotrexate, and for users of medicines in general.

Nevertheless, the results demonstrate strongly that for some methotrexate users, the design of the packaging and labelling is so unsuitable that they are completely unable to access their medicines without the provision of outside assistance. The design exclusion assessment carried out during this research also supports this finding. An indirect result of such user-unfriendly design is that methotrexate patients adopt a variety of "coping strategies", which may also lead to further decreases in their safety and for the safety of third parties such as children.

Whilst the findings relate specifically to users of methotrexate, who may experience particular difficulties in accessing medicines due to their medical conditions, other research shows that older users also experience similar difficulties. The findings and the recommendations from this study may also, therefore, be broadly applicable to medicines in general.

The study underscores the importance of not only good packaging and labelling design but the design of the system that supports the safe use of medication. As a result of this and other related research, systems-wide changes have already been implemented across the NHS. It is hoped that the results from this study will continue to both motivate and inform the development of more appropriate solutions for patients in the future, through improved packaging design and through changes to the related healthcare system.

\section{Acknowledgements}

The authors would like to express their thanks to the patients, healthcare professionals and GP practices for taking part in this study, to the NPSA for its sponsorship of the research and to a significant number of individuals who assisted with the other aspects of the project; particularly Wendy Harris of the NPSA and Dr Stephen Barclay of the General Practice \& Primary Care Research Unit at the University of Cambridge for their helpful guidance.

\section{References}

Adcock, H., 2004. Safe methotrexate use: pharmacy's role. The Pharmaceutical Journal 273 (7310), 144

Atkin, P.A., Finnegan, T.P., Ogle, S.J., 1994. Functional ability of patients to manage medication packaging: a survey of geriatric inpatients. Age and Ageing 23, 113-116.

Audit Commission, December 2001. A Spoonful of Sugar. Report. Audit Commission, London.

Beckman, A.G.K., Parker, M.G., Thorslund, M., 2005. Can elderly people take their medicine? Patient Education and Counseling 59 (2005), 186-191.

Bernardini, C., Ambrogi, V., Fardella, G., Perioli, L., Grandolini, G., 2001. How to improve the readability of the patient package leaflet: a survey on the use of colour, print size and layout. Pharmacological Research 43 (5), 437-444.

Bernardini, C., Ambrogi, V., Perioli, L., Tiralti, M., Fardella, G., 2000. Comprehensibility of the package leaflets of all medicinal products for human use: a questionnaire survey about the use of symbols and pictograms. Pharmacological Research 41 (6), 679-688.

BMJ, October 2003. Minerva. British Medical Journal 327 (11), 878.

Braus, P., Jan 1993. Did you take your medicine. American Demographics, 14-15.

Buckle, P., Clarkson, P.J., Coleman, R., Ward, J., Anderson, J., 2006. Patient safety, systems design and ergonomics. Applied Ergonomics 37 (4), 491-500.

Carayon, P., Schoofs Hundt, A., Karsh, B.T., Gurses, A.P., Alvarado, C.J., Smith, M., Flatley Brennan, P., 2006. Work system design for patient safety: the SEIPS model. Quality and Safety in Health Care 15 (Suppl. 1), i50-i58.

CHA, 2000. Methotrexate Toxicity: an Inquiry into the Death of a Cambridgeshire Patient in April 2000. Cambridgeshire Health Authority, Cambridge. Report, July.

Clark, P., 2002. An Ergonomic Evaluation of prescrIption Medicine Packaging and Labelling for the Elderly. Masters thesis, London University, London.

Clarkson, P.J., Buckle, P., Coleman, R., Stubbs, D., Ward, J.R., Jarrett, J., Lane, R., Bound, J., 2004. Design for patient safety: a review of the effectiveness of design in the UK health service. Journal of Engineering Design 15 (2), 123-140. 
Clarkson, P.J., Coleman, R., Hosking, I., Waller, S., 2007. Inclusive Design Toolkit. Engineering Design Centre, University of Cambridge, Cambridge, UK.

Clarkson, P.J., Dong, H., Keates, S., 2003. Quantifying design exclusion. In: Clarkson, J., Keates, S., Coleman, R., Lebbon, C. (Eds.), Inclusive Design: Design for the Whole Population. Springer-Verlag, London, pp. 423-436.

Cramer, J.A., 1998. Enhancing patient compliance in the elderly: role of packaging aids and monitoring. Drugs \& Aging 12 (1), 7-15.

DH, 1998. Report. Health Survey for England, vol. 1. Department of Health, London.

DH, 2004. Building a Safer NHS for Patients: Improving Medication Safety. Report. Department of Health, London.

Donaghy, A., Wright, D., 2003. Standardising risk assessment to reduce unintentional non-compliance in aged patients pre-discharge. International Journal of Pharmacy Practice 11 (Suppl.), R51.

DTI, 1999. Assessment of Broad Age-related Issues for Package Opening. Report. Department of Trade and Industry, London.

Grundy, E., Ahlburg, D., Ali, M., Breeze, E., Sloggett, A., 1999. Disability in Great Britain: Results from the 1996/7 Disability Follow-up to the Family Resources Survey. Report. Department of Social Security, London.

Harris, W., 2005. Methotrexate-associated medication errors. American Journal of Health-System Pharmacy 61 (24), 2635.

Hughes, R.A., Carr, A.J., Carr, M., Walsh, M., 2008. Improving patient safety: reducing medication errors through use of acceptable, accessible medicines packaging. The Pharmaceutical Journal 280 (7484), 22-25.

HMSO, 2000. The NHS Plan. Report. The Stationery Office, London.

Kalsher, M., Wogalter, M., Racicot, B., 1996. Pharmaceutical container labels: enhancing preference perceptions with alternative designs and pictorials. International Journal of Industrial Ergonomics 18 (1), 83-90.

Kenagy, J.W., Stein, G.C., 2001. Naming, labeling, and packaging of pharmaceuticals. American Journal of Health-System Pharmacy 58 (1), 2033-2041.

Kerr, K., Higham, C., Cox, A.R., Situnayake, R.D., 2003. A determination of patient awareness of the safety issues surrounding treatment with methotrexate. Pharmaceutical Journal 270, 900-901.

Marinker, M., Shaw, J., 15 February 2003. Not to be taken as directed: putting concordance for taking medicines into practice. British Medical Journal 326 348-349.

Martin, J., Meltzer, H., Elliot, D., 1988. The Prevalence of Disability Among Adults. Her Majesty's Stationery Office, London, UK.
Mawle, R., 2003. Which Pill When: Packaging That Aids Compliance in Taking Medication. Masters thesis, Royal College of Art, London.

MCA, 2003. Best Practice Guidance on the Labelling and Packaging of Medicines. MHRA Guidance Note No. 25, June. Medicines Control Agency, London.

Moisan, J., Gaudet, M., Gregoire, J.-P., Bouchard, R., 2002. Non-compliance with drug treatment and reading difficulties with regard to prescription labelling among seniors. Gerontology 48 (1), 45-51.

NPSA, 2003. Patient Safety Alert 03, Reducing harm Caused by Oral Methotrexate. National Patient Safety Agency, London.

NPSA, 1 June 2006. Improving compliance with oral methotrexate guidelines. http://www.npsa.nhs.uk/patientsafety/alerts-and-directives/alerts/oralmethotrexate/ [accessed July 2008].

NPSA, 2007a. Design for Patient Safety: A Guide to the Graphic Design of Medication Packaging, second ed. National Patient Safety Agency and the Helen Hamlyn Research Centre, Royal College of Art, London.

NPSA, 2007b. Design for Patient Safety: A Guide to the Design of Dispensed Medicines. National Patient Safety Agency, London.

NPSA, 2007c. Design for Patient Safety: A Guide to the Design of the Dispensing Environment. National Patient Safety Agency, London.

Sansgiry, S.S., Cady, P.S., Patil, S., 1997. Readability of over-the-counter medication labels. Journal of the American Pharmaceutical Association NS37 (5), 522-528.

Semmence, J., Gault, S., Hussain, M., Hall, P., Stanborough, J., Pickering, E., 1998 Family Resources Survey - Great Britain 1996-97. Department of Social Security, Corporate Document Services, London.

The Information Centre, 2008. Prescriptions Dispensed in the Community. Statistics for 1997 to 2007: England. The Information Centre, Leeds.

Thwaites, J., 1999. Practical aspects of drug treatment in elderly patients with mobility problems. Drugs \& Aging 14 (2), 105-114.

Toogood, H., 2002. Packaging for a Safer Future in the Use of Medicines. Pharmaceutical Manufacturing and Packing Sourcer. http://www.samedanltd.com/ magazine/15/issue/65/article/1616 [accessed June 2008].

Ward, J.R., Clarkson, P.J., Buckle, P., April 2004. The Packaging and Labelling of Solid Oral Medicines: a Study to Identify the Needs and Functionality for Safe Administration of Solid Oral Medicines Using Oral Methotrexate as an Example. Report. Engineering Design Centre, University of Cambridge, UK, Cambridge.

Wright, E.C., 1993. Non-compliance - or how many aunts has Matilda? The Lancet 342 (8876), 909-913. 